\title{
ANALISIS SISTEM INFORMASI KESEHATAN PADA PELAYANAN REKAM MEDIS DI RUMAH SAKIT PELAMONIA TK.II MAKASSAR
}

\author{
Analysis Of Health Information System In Medical Record Service \\ At Pelamonia Hospital Tk.II Of Makassar
}

\author{
Andi Ayumar ${ }^{*}$, Andi Yulia Kasma ${ }^{2}$, Andi Pratiwi Rachmadhani ${ }^{3}$ \\ Sekolah Tinggi Ilmu Kesehatan Makassar
}

*Korespondensi: andiayumar@gmail.com

\begin{abstract}
ABSTRAK
Pencatatan data riwayat kesehatan pasien adalah hal yang penting dalam dunia medis dan dikenal dengan istilah data rekam medis. Selama pasien melakukan pemeriksaan atau menjalani perawatan medis oleh dokter atau suatu instansi medis, maka status kesehatan pasien akan dicatat sebagai data rekam medis pasien. Penelitian ini bertujuan untuk mengetahui analisis sistem informasi kesehatan pada pelayanan rekam medis di Rumah Sakit Pelamonia Tk.II Makassar Tahun 2019. Penelitian ini merupakan penelitian deskriptif eksploratif yang menggambarkan keadaan suatu fenomena, dalam penelitian ini tidak dimaksud untuk menguji hipotesis tertentu tetapi hanya menggambarkan apa adanya suatu variabel, gejala atau keadaan. Berdasarkan hasil penelitian yang telah di lakukan dalam menganalisis sistem informasi kesehatan pada pelayanan rekam medis di Rumah Sakit Pelamonia Tk.II Makassar yang sesuai dengan SOP rekam medis. Simpulan dari penelitian ini yaitu sistem informasi kesehatan pada pelayanan rekam medis di Rumah Sakit Pelamonia Tk.II Makassar sudah sesuai dengan SOP yang telah ditetapkan oleh Karumkit Tk.II 07.05.01 Pelamonia Nomor Kep/205/AK/IX/2014 tanggal 09 September 2014 tentang Keamanan Data dan Informasi. Sebagai saran, agar rumah sakit khususnya bagian rekam medis mempertahankan bahkan lebih meningkatkan kinerjanya untuk melayani pasien.
\end{abstract}

Kata Kunci : Sistem informasi kesehatan, rekam medis

\section{ABSTRACT}

Recording of patient health history data is important in the medical world and is known as medical record data. As long as the patient is examined or undergone medical treatment by a doctor or a medical institution, the patient's health status will be recorded as the patient's medical record. This study aimed to find out the analysis of health information system in medical record service at Pelamonia Hospital TK.II of Makassar in 2019. This research was an explorative descriptive research that described the state of a phenomenon, this study was not only intended to test a particular hypothesis but only describes the existence of a variable, symptom or circumstance. Based on the results of research that had been done in analyzing the health information system in medical record service at The Hospital Pelamonia TK.II of Makassar in accordance with the standard operating prosedures medical records. Conclusion of this research is health information system in medical record service at Pelamonia Hospital Tk.II Makassar is in accordance with standard operating prosedures that has been determined by Karumkit TK.II 07.05.01 Pelamonia Number Kep/205/AK/IX/2014 dated September 9, 2014 on Data and Information Security. As a suggestion, for hospitals, especially the medical records section, to maintain even more performance-enhancing to serve patients.

Keywords: Health information system, medical record. 


\section{PENDAHULUAN}

Rumah sakit sebagai salah institusi yang menyelenggarakan pelayanan umum membutuhkan keberadaan sistem informasi yang akurat untuk meningkatkan pelayanan kepada para pasien serta lingkungan terkait lainnya. Untuk mencari kekurangan ataupun kelebihan sistem diperlukan suatu analisis sistem. Analisis Sistem merupakan kegiatan yang menganalisa sebuah sistem dengan tujuan untuk menyelesaikan dan memberikan solusi terhadap apa yang dibutuhkan (Taufiq, 2013 dalam Prasaja, 2014).

Dewasa ini, sistem informasi yang digunakan lebih berfokus pada sistem informasi berbasis komputer (computer-based information system). Sistem Informasi Manajemen (SIM) berbasis komputer merupakan sarana pendukung yang sangat penting bahkan bisa dikatakan mutlak untuk operasional sebuah rumah sakit. Berbagai pengalaman rumah sakit yang menggunakan sistem administrasi konvensional, menunjukkan banyaknya kehilangan kesempatan memperoleh laba akibat dari lemahnya koordinasi antar departemen maupun kurangnya dukungan informasi yang cepat, tepat, akurat, dan terintegrasi (Wajirah, 2010).

Sistem Informasi Manajemen Rumah Sakit (SIM RS) adalah suatu rangkaian kegiatan yang mencakup semua pelayanan kesehatan (rumah sakit) disemua tingkatan administrasi yang dapat memberikan informasi kepada pengelola untuk proses manajemen pelayanan kesehatan di rumah sakit. Peran sistem informasi didalam kegiatan manajemen rumah sakit sangatlah membantu dan mempunyai peran yang sangat efektif dalam proses pelayanan kesehatan di rumah sakit, dengan sistem informasi seorang pemimpin rumah sakit dapat mengambil suatu kebijakan secara cepat, tepat dan akurat berdasarkan informasi yang didapat dari pelayanan kesehatan di rumah sakit yang dipimpinnya (Rustiyanto, 2010 dalam Topan 2015).

Data rekam medis Rumah Sakit Tk.II Pelamonia Makassar dari tahun 2016-2018 terjadi penurunan jumlah kunjungan pasien setiap tahunnya. Pada ttahun 2016 data kunjungan pasien sebanyak 4.407 kunjungan, kemudian di tahun selanjutnya pada tahun 2017 mengalami penurunan jumlah kunjungan yaitu 4.045 kunjungan. Hal ini berlaku pada di tahun 2018 jumlah kunjungan pasien kembali mengalami penurunan jumlah kunjungan pasien mencapai 3.865 kunjungan. Melihatnya besar angka ini maka diperlukan sistem pencatatan yang baik pada setiap lingkup pelayanan kesehatan di seluruh Indonesia terkhusus di Sulawesi Selatan.

Berdasarkan observasi pendahuluan yang telah dilakukan dibeberapa rumah sakit, sistem informasi rumah sakitnya sudah menggunakan komputer tetapi mempunyai masalah seperti penginputan data pasien yang double, data pasien tidak terinput, terdapat pasien yang sama nomor rekam medisnya. Untuk sistem informasi rekam medis di Rumah Sakit Plamonia Tk.II Makassar sudah 
menggunakan sistem informasi berbasis komputer, dengan jumlah petugas rekam medis 9 orang, dan operator 1 orang. Sistem informasi berbasis komputer merupakan sarana pendukung yang sangat penting bahkan bisa dikatakan mutlak untuk operasional sebuah rumah sakit. Terdapat beberapa kendala yang menghambat proses penginputan sistem informasi rumah sakit, diantaranya kekurangan jumlah tenaga operator, terlambatnya penyetoran berkas rekam medis pasien, dan jaringan yang lambat.

Oleh sebab itu, peneliti tertarik untuk mengetahui bagaimana sistem informasi kesehatan pada pelayanan rekam medis di Rumah Sakit Tk.II Pelamonia Makassar.

\section{BAHAN DAN METODE}

Penelitian deskriptif eksploratif yang bertujuan untuk mengetahui bagaimana sistem informasi kesehatan pada bagian rekam medis di Rumah Sakit Pelamonia Tk.II Makassar. Dalam penelitian ini peneliti melakukan wawancara dengan 3 informan. Kepala Bidang rekam medik sebagai informan kunci sedangkan untuk informan pendukung yaitu petugas rekam medis dengan petugas pendaftaran.

Hasil wawancara dengan 3 informan akan dibandingkan dengan SOP rekam medis yang telah ditetapkan oleh Karumkit Tk.II $07.0501 \quad$ Pelamonia Nomor Kep/205/AK/IX/2014. Apakah sistem informasi kesehatan sudah sesuai dengan SOP atau tidak.

\section{HASIL}

Dari hasil penelitian yang telah dilakukan diruang rekam medis Rumah Sakit Pelamonia Tk.II Makassar, terdapat Standar Operasional Prosedur (SOP) di masing-masing bagian yang terdapat dalam protap pengelolaan rekam medis. Informan kunci mengatakan adanya SOP kerja petugas dan paham tentang prosedur kerjanya.

Selanjutnya dilakukan observasi kembali untuk melihat kesesuaian hasil wawancara petugas dengan peneliti. Hasilnya dibagian pendaftaran, petugas pendaftaran sudah melayani pasien dengan baik, dapat menjawab apabila pasien menanyakan suatu hal serta dapat menerima keluhan-keluhan dari pasien. Tetapi ada sebagian petugas yang kurang cepat/tanggap dalam melayani pasien, sehingga ada beberapa mengeluhkan pelayanan yang lama dari petugas.

Dari beberapa pasien yang sempat diwawancarai, ada yang merasa puas dan ada juga beberapa merasa kurang puas terkait pelayanan dirumah sakit, baik diruang pendaftaran maupun di bagian poli. Di ruang pendaftaran, pasien merasa tidak nyaman/kepanasan saat berada diruang tunggu, pelayanan dari petugas yang tidak tepat waktu (kemungkinan dari petugas yang terlambat datang atau mungkin pasien yang merasa jenuh).

Didepan ruangan rekam medis, terlihat banyak berkas pasien tersimpan diluar ruangan, kemudian petugas masih kewalahan saat mencari berkas pasien maupun pada saat 
http://journal.unpacti.ac.id/index.php/JPP

penginputan data dikarenakan kurangnya petugas yang bertanggung jawab dalam menginput data pasien.

\section{PEMBAHASAN}

Sistem informasi rekam medik adalah proses yang berhubungan dengan pencatatan data yang ada pada pasien serta bagaimana mengelola dan melakukan pencarian kembali terhadap status pasien yang berisi: data identitas pasien, resume hasil anamnesi, resume hasil pemeriksaan fisik, resume terapi, alergi obat dan lain-lain (Sabarguna, 2005 dalam Afriani, 2016).

Keputusan Menteri Kesehatan Republik Indonesia Nomor: 377/Menkes/SK/III/2007 menyebutkan bahwa petugas rekam medis yang profesional wajib memberikan pelayanan yang berkualitas sesuai dengan standar kompetensi dan kode etik profesi. Kompetensi petugas rekam medis yaitu: Klasifikasi dan kodifikasi penyakit, masalah-masalah yang berkaitan dengan kesehatan dan tindakan medis, aspek hukum dan etika profesi, Manajemen rekam medis dan informasi kesehatan. Menjaga mutu rekam medis, statistik kesehatan, manajemen unit kerja informasi kesehatan/rekam medis, Kemitraan profesi (Dindatia, 2016).

\section{Penerimaan / Pendaftaran Pasien.}

Penerimaan / Pendaftaran Pasien

merupakan pintu masuk pertama dalam penerimaan dan pendaftaran pasien. Kegiatan rekam medis yang berkaitan dengan penerimaan pasien/ pendaftaran dijelaskan sebagai berikut:

1. Setiap pasien yang diterima di tempat penerimaan pasien (TPP) ditanya oleh petugas untuk mendapatkan data identitas yang akan diisikan pada formulir Ringkasan Riwayat Klinik.

2. Setiap pasien akan memperoleh nomor pasien yang akan digunakan sebagai nomor kartu pengenal. Kartu pengenal harus dibawa pada kunjungan berikutnya, baik sebagai pasien rawat jalan maupun pasien rawat inap.

3. Berkas rekam medis pasien baru akan dikirim oleh petugas sesuai dengan poliklinik yang dituju.

4. Berkas pasien yang harus dirawat akan dikirim keruang perawatan

\section{Menghitung Dan Memperkirakan Biaya Tindakan Operasi.}

Dalam penentuan tarif layanan, penting untuk menghitung secara akurat berapa biaya satuan yang dibutuhkan untuk menghasilkan layanan tersebut. Tingkat pemulihan biaya layanan pun dapat dihitung untuk mengetahui apakah layanan tersebut merugikan atau menguntungkan bagi rumah sakit. Masalah biaya pelayanan merupakan hal yang sangat penting sehingga mendorong seluruh elemen yang berkepentingan, untuk menghitung secara riil berapa biaya pelayanan yang dibutuhkan (Aurelia, 2015). 
Memberikan Informasi Pelayanan Dan Produk Rumah Sakit Sesuai Permintaan Pelanggan.

Pelayanan yang optimal dalam sistem informasi pelayanan rekam medis di Rumah Sakit Angkatan Udara Dr. Hoediyono didukung dengan budaya kerja, kepatuhan dan ketaatan tenaga kesehatan dalam memberikan pelayanan pasien mengingat Rumah Sakit Angkatan Udara Dr. Hoediyono adalah rumah sakit militer. Budaya kerja, merupakan kelompok pola perilaku yang melekat secara keseluruhan pada diri setiap individu dalam sebuah organisasi. Membangun budaya berarti juga meningkatkan dan mempertahankan sisisisi positif, serta berupaya membiasakan (habituating process) pola perilaku tertentu agar tercipta suatu bentuk baru yang lebih baik berdasarkan kepatuhan dan ketaatan setiap individu (Habibiarifin, 2018).

\section{Menerima Dan Menangani Komplain Pelanggan Secara Profesional.} Dalam penelitian Irawan, (2016) tentang "Manajemen Komplain Dalam Pelayanan Kesehatan Di Rumah Sakit Umum Daerah Merauke" hasilnya membahas bahwa manajemen komplain dalam pelayanan kesehatan di RSUD Merauke belum menunjukkan hasil yang baik. Masih ada beberapa hal yang harus diperbaiki, yaitu hanya ada kotak saran sebagai alternative menerima keluhan yang masuk secara tidak langsung, dan dalam penangannyapun belum maksimal. Hal ini terbukti dari masih lambatnya pengelolaan serta tidak adanya penyampaian informasi dari rumah sakit kepada pasien bahwa keluhan yang masuk sudah ditangani.

\section{Melakukan Pekerjaan Administrasi Yang Terkait Dengan Pelayanan Pelanggan.}

Berdasarkan penelitian yang pernah dilakukan sebelumnya menurut Cholifah menyatakan bahwa pelaksanaan evaluasi kebutuhan tenaga kerja berdasarkan beban kerja sub Bidang Rekam Medis yang sesuai dengan kebutuhan akan dapat menunjang penyelenggaraan Rekam Medis yang maksimal. Melihat besarnya peranan pelayanan rekam medis dalam pelayanan rumah sakit, maka sudah saatnya perlu mendapatkan perhatian yang tinggi terkait halhal apa saja yang menunjang demi peningkatan kualitas terbaik di instalasi rekam medis (Hasibuan, 2014).

\section{Memberikan penjelasan/informasi kepada pasien tentang jadwal hari pelayanan di poliklinik Rumkit Tk.II Pelamonia.}

Menurut Candra dalam Khairani, salah satu indikator kepuasan pasien adalah waktu tunggu, waktu tunggu yang lama terhadap pelayanan medis maupun non medis pada unit rawat jalan dan rawat inap akan mengurangi kepuasan pasien. Masalah yang sering muncul diinstalasi rawat jalan adalah lamanyawaktu tunggu penyampaian data rekam medis pasien ke meja dokter, sehingga diperlukan sistem informasi manajemen rumah sakit yang bagus untuk mempercepat proses pencarian data pasien. Masalah utama lain yang sering terjadi di sebagian besar rumah sakit di Indonesia adalah lamanya waktu tunggu akibat 
keterlambatan kedatangan dokter yang tidak sesuai dengan jadwal pelayanan poliklinik. Oleh karena itu sangat penting untuk memberikan informasi kepada pasien tentang jadwal pelayanan di poliklinik.

\section{Memberikan informasi kepada pasien} tentang rumah sakit.

Dengan melihat beberapa aspek tersebut, rekam medis mempunyai kegunaan yang sangat luas, karena tidak hanya menyangkut antara pasien dengan pemberi pelayanan saja. Manfaat rekam medis secara umum adalah :

a. Sebagai media komunikasi antara dokter dan tenaga ahli lainnya yang ikut ambil bagian di dalam memberikan pelayanan, pengobatan, dan perawatan kepada pasien.

b. Menyediakan data yang berguna bagi keperluan penelitian dan pendidikan.

c. Sebagai dasar untuk merencanakan pengobatan atau perawatan yang harus diberikan kepada pasien.

d. Sebagai bukti tertulis atas segala tindakan pelayanan perkembangan penyakit dan pengobatan selama pasien berkunjung atau dirawat di rumah sakit.

e. Sebagai dasar yang berguna untuk analisis, penelitian, dan evaluasi terhadap kualitas pelayanan yang diberikan kepada pasien.

f. Melindungi kepentingan hukum bagi pasien, rumah sakit maupun dokter, dan tenaga kesehatan lainnya.

g Sebagai dasar dalam perhitungan pembayaran pelayanan medis pasien. h. Menjadi sumber ingatan yang harus didokumentasikan, serta bahan pertanggung jawaban dan laporan.

\section{Memberikan penjelasan tentang asuransi kepada pasien dinas, pasien umum, dan pasien BPJS mandiri.}

a. Pasien Dinas adalah pasien yang bekerja di lembaga pemerintahan seperti Pegawai Negeri Sipil, anggota TNI, anggota Polri, pejabat negara, dan pegawai pemerintah non-PNS.

b. Pasien umum adalah Pasien umum ialah pasien bukan peserta BPJS dan bukan peserta asuransi.

c. Pasien BPJS mandiri adalah Peserta BPJS Mandiri yaitu peserta yang merupakan rakyat biasa yang terdiri dari Petani, Nelayan, Pedagang, tukang ojek dan lainlainnya yang mendapatkan jaminan kesehatan. Badan Penyelenggara Jaminan Sosial (BPJS) Kesehatan merupakan suatu badan yang dibuat oleh pemerintah dimana ditugaskan untuk mengatur jaminan sosial kesehatan masyarakat (Sari, 2015).

Memberikan penjelasan kepada pasien apabila ada pasien yang ingin naik kelas mengenai prosedur untuk mengubah kelas perawatan.

Ketentuan naik kelas perawatan diatur oleh Peraturan Presiden Nomor 12 tahun 2013 tentang Jaminan Kesehatan pasal 24. Ketentuan tersebut diperjelas dengan Peraturan Menteri Kesehatan No. 28/ 2014 tentang Pedoman Pelaksanaan Program Jaminan 
Kesehatan Nasional Bab IV bagian E tentang

Peningkatan Kelas Perawatan. Bagi pasien yang naik kelas perawatan maka besaran iuran biaya adalah selisih antara biaya kelas yang diminta dikurangi biaya kelas sesuai haknya. Peserta dapat juga memutuskan naik kelas perawatan akibat kamar yang sesuai hak kelas rawat penuh. Ini bisa saja terjadi bila kapasitas tempat tidur dan kebutuhannya pada kelas yang ada tidak berimbang pada sebuah rumah sakit. Banyaknya permintaan tidak selalu diimbangi dengan ketersediaan ruang kelas rawat yang sesuai (Palupi, dkk 2016).

Koordinasi dengan ruang perawatan mengenai kedaan tempat tidur untuk pasien yang akan masuk ruang rawat inap.

Dalam penelitian Dewi (2015) yaitu

Komponen yang terlibat dalam proses penerimaan pasien rawat inap dari rawat jalan adalah SDM yaitu dokter pol, perawat, asisten perawat, petugas pendaftaran, petugas farmasi, petugas kasir dan SOP yang sudah ada tetapi belum dibuat secara terperinci tahap-tahapnya serta SIRS yang belum terintegrasi secara online dengan semua unit di RS “X”.

\section{KESIMPULAN DAN SARAN}

Berdasarkan hasil penelitian, ditarik kesimpulan bahwa sistem informasi kesehatan pada pelayanan rekam medis di Rumah Sakit Pelamonia Tk.II Makassar sudah sesuai dengan SOP yang ada, namun kurangnya petugas penginputan menyebabkan masih banyak berkas status pasien yang tersimpan di luar ruangan dan beberapa pasien mengeluhkan pelayanan yang diberikan karena lamanya menunggu antrian serta pengurusan berkas pasien yang dianggap berbelit-belit.

Perlunya peningkatan kinerja petugas rekam medis dalam mengurus berkas status pasien serta dapat lebih cepat memberikan tindakan ketika pasien memiliki keluhan ataupun keperluan.

\section{DAFTAR PUSTAKA}

Afriany, R.N dan Purnama, B. 2016. Analisis Dan Perancangan Sistem Informasi Rekam Medis Di Rumah Sakit Tk. IV Dr. Bratanata Jambi.

Aurelia,A dan Pujiyanti, E. 2015. Biaya Satuan dan Pemulihan Biaya (Cost Recovery Rate) Layanan Pasien Acute Coronary Syndrome dengan Rawat Inap di Rumah Sakit X Tahun 2015.

Dindatia, N,. Junaid, dan Rasama. Gambaran Kinerja Petugas Rekam Medik Di Rumah Sakit Umum Daerahkota Kendari Tahun 2017. Jurnal Ilmiah Mahasiswa Kesehatan Masyarakat Vol.2.No.6/Mei2017; Issn 2502-7311x.

Dewi, P.K. 2015. Analisis Alur Proses Penerimaan Pasien Rawat Inap di Rumah Sakit " $X$ ” Tahun 2015 dengan Pendekatan Lean Hospital. Jurnal ARSI/Oktober 2015.

Hasibuan, dkk. 2014. Analisis Standar Kebutuhan Tenaga Rekam Medis Berdasarkan Beban Kerja di Instalasi Rekam Medis Rumah Sakit Ken Saras Tahun 2013. Jurnal Kesehatan Masyarakat (E-Journal), Volume 2, Nomor 2, Februari.2014

Palupi, dkk. 2016. Determinan Pilihan Naik Kelas Perawatan Rumah Sakit Dari Kelas I Ke Kelas Vip. Jurnal Kebijakan Kesehatan Indonesia, Vol. 05, No. 4 Desember 2016 
http://journal.unpacti.ac.id/index.php/JPP

Prasaja, H,S. 2014. Analisis Sistem Informasi Registrasi Pasien di Rumah Sakit Umum Asy-Syifa Sambi Boyolali. Surakarta.

Rustiyanto, E. 2010. Sistem Informasi Manajemen Rumah Sakit Yang Terintegrasi, Yogyakarta Goysen Publhising.

Sari, F, P. 2015. Persepsi Masyarakat Pengguna Badan Penyelenggara Jaminan Sosial (Bpjs) Kesehatan
Mandiri Dalam Pelayanan Rsud Lubuk Basung Kabupaten Agam. Jom FISIP Volume 2 No. 2 - Oktober 2015.

Taufiq R. 2013. Sistem Informasi Manajemen. Konsep Dasar, Analisis dan Metode Pengembangan. Yogyakarta : Graha Ilmu.

Wajirah. 2010. Sistem Informasi Pelayanan Kesehatan di Rumah Sakit Umum Daerah (RSUD) Kabupaten Cilacap. Surakarta. 